\title{
Peer Education Meningkatkan Perilaku dalam Mencegah Penularan Tuberkulosis Paru pada Keluarga
}

\author{
Sunarsih Rahayu ${ }^{1 *}$, Ros Endah Happy Patriyani \\ ${ }^{1,2}$ Jurusan Keperawatan, Poltekkes Kemenkes Surakarta \\ *Email : sunarsihr@yahoo.com
}

\begin{abstract}
Background: Pulmonary tuberculosis is an important public health problem in the world. In 1992, the World Health Organization (WHO) declared pulmonary tuberculosis as a "global emergency". Indonesia is committed to ending pulmonary tuberculosis as a "public health problem" in 2030. Peer education is the proper media and method to provide counseling on prevention of pulmonary tuberculosis transmission. This study was conducted to determine the effect of peer education on behavior change in preventing pulmonary tuberculosis transmission in families of Sibela and Sangkrah Health Center's work area in Surakarta. Methods: This research is a quasi-experimental study with pre post-test control group design. Data analysis using dependent t-test and independent t-test. Results: The results of the dependent $t$ test in the intervention group showed p-value $=0,000$ on knowledge, attitudes, and behavior, while the control group showed results $p$-value $=0.003$ on knowledge, $p$-value $=0.057$ on attitudes, and $p$-value $=0.004$ on behavior. Independent t test shows the results of p-value $=0,000$ in knowledge, $p$ value $=0.002$ in attitudes, and p-value $=0.778$ in behavior. Conclusion: Based upon these results it can be concluded that there is an influence of peer education on changes in knowledge, attitudes, and behaviors in pulmonary tuberculosis transmission prevention, as well as differences in knowledge and attitudes, but there is no difference in behavior between respondents with and without peer education.
\end{abstract}

Keyword: behavior change, peer education, pulmonary tuberculosis

\section{PENDAHULUAN}

Tuberkulosis (TB) paru merupakan penyakit menular yang banyak terjadi di berbagai negara di dunia, termasuk Indonesia. Penyakit ini menjadi masalah besar yang secara umum dianggap sebagai ancaman terhadap jiwa manusia. Pusat Data dan Informasi Kemenkes RI pada tahun 2018, mencatat ada sekitar 10,4 juta orang menderita TB paru di tahun 2016, dan Indonesia berada pada posisi lima besar negara dengan kasus TB paru tertinggi.

Menurut laporan WHO, Indonesia merupakan salah satu negara yang mempunyai insiden TB paru tertinggi di dunia dan angka kejadian TB paru menempati peringkat ketiga di dunia. Pada tahun 2018, insiden TB paru di Indonesia adalah 316 per 100.000 penduduk, sementara itu sekitar 845.000 penduduk menderita TB paru. Beban TB paru lebih tinggi di perkotaan dibandingkan dengan pedesaan (Kemenkes RI, 2020). Berdasarkan laporan WHO tahun 2019, pada tahun 2018 diperkirakan angka kematian TB paru di Indonesia adalah 35 per 100.000 penduduk artinya sekitar 93.000 orang meninggal karena TB paru. Jumlah laporan kasus TB paru pada tahun 2018 adalah 565.869 kasus, sementara jumlah penemuan kasus TB paru pada Global TB Report 2019 adalah sebesar 570.289 kasus (Kemenkes RI, 2020).

TB paru adalah tantangan untuk pembangunan Indonesia karena $75 \%$ pasien TB paru terjadi pada rentang usia remaja sampai lansia yaitu 15-54 tahun. Pada usia tersebut, pasien seharusnya masih mempunyai penghasilan yang optimal. Lebih dari 25 persen pasien TB paru dan 50 persen pasien $\mathrm{TB}$ paru 
resisten obat mempunyai risiko menurunnya produktivitas atau kehilangan pekerjaan akibat kecacatan, pengeluaran biaya yang besar untuk pengobatan, transportasi dan pemenuhan nutrisi. Kesulitan ekonomi yang secara langsung dan tidak langsung akibat TB paru menimbulkan halangan akses terhadap diagnosis dan pengobatan, yang dapat memperburuk hasil pengobatan serta meningkatkan risiko penularan infeksi di masyarakat (Kemenkes RI, 2020).

Pada tahun 2017, di Puskesmas Sibela Surakarta terdapat kasus TB paru (Bakteri Tahan Asam) BTA positif sejumlah 16 orang, dan di Puskesmas Sangkrah sejumlah 35 orang. Salah satu perawat di Puskesmas Sibela Surakarta mengatakan, rata-rata pasien kurang kesadaran dalam pencegahan penularan, antara lain ketika batuk mulut tidak ditutup dan meludah di sembarang tempat. Dengan perilaku yang demikian, tidak menutup kemungkinan penularan TB paru akan mudah terjadi ke orang lain terutama kepada keluarga yang terdekat. Merujuk kepada arahan Presiden pada kegiatan gerakan bersama menuju eliminasi TB paru tahun 2030, bahwa upaya penanggulangan TB paru tidak hanya pada penanganannya saja namun dimulai dari pencegahan, dan diharapkan semua pihak bergerak bersama untuk melaksanakan upaya eliminasi TB paru untuk mewujudkan lingkungan dan negara yang bebas TB paru (Kemenkes RI, 2020).

Gerakan bersama untuk mencapai eliminasi TB paru tahun 2030 ini dilakukan dengan cara menyebarluaskan informasi TB paru kepada masyarakat untuk meningkatkan pengetahuan dan kepedulian terkait dengan pencegahan penularan TB paru yang dimulai dari diri sendiri dan keluarga. Peer education menjadi salah satu alternatif cara yang dapat digunakan oleh petugas kesehatan untuk memberikan penyuluhan kepada masyarakat khususnya pasien TB paru tentang TB paru dan pencegahannya, sehingga mereka sadar dan mau untuk merubah perilaku. Perubahan perilaku ini sebagai wujud dukungan untuk mencapai eliminasi TB paru tahun 2030.

Dalam penelitian yang dilakukan oleh Putra SD (2018) dengan judul media pembelajaran dan sosialisasi penyakit TB, dikatakan bahwa masyarakat akan lebih mudah mempelajari suatu penyakit jika dikemas menggunakan media pembelajaran yang tepat dan sederhana. Tujuan akhir dari penelitian ini yaitu untuk mengetahui apakah peer education berpengaruh terhadap perubahan perilaku pasien TB paru dalam pencegahan penularan TB paru pada keluarga di Puskesmas Sibela dan Sangkrah Surakarta.

\section{METODE PENELITIAN}

Metode penelitian yang digunakan adalah kuasi eksperimen dimana pengambilan data responden dilakukan sebelum intervensi dan setelah intervensi. Penelitian dilakukan bulan April-Juli 2019 di Puskesmas Sibela dan Puskesmas Sangkrah Surakarta. Persetujuan etik penelitian ini dikeluarkan oleh Komisi Etik Penelitian Kesehatan RSUD Dr.Moewardi di Surakarta. Sampel yang digunakan sebanyak 60 orang dengan kriteria responden BTA positif. Responden di Puskesmas Sibela sejumlah 30 orang sebagai kelompok intervensi dan responden di Puskesmas Sangkrah sejumlah 30 orang sebagai kelompok kontrol, dengan concecutive sampling. 
Peer education sebagai variabel independen dilakukan pada responden kelompok intervensi, dan perilaku pencegahan TB sebagai variabel dependen yang akan diobservasi sebelum dan sesudah dilakukan peer education. Instrumen penelitian yang digunakan adalah kuesioner yang berisi tentang pengetahuan TB paru dan sikap pasien terhadap pencegahan penularan TB paru, dan ceklist yang berisi tindakan atau perilaku pasien untuk mencegah penularan penyakit ke keluarga. Responden kelompok intervensi, instrumen diberikan sebelum dan sesudah peer education. Responden kelompok kontrol, peer education dilakukan setelah pengambilan data kedua.

Peer education dilakukan dengan cara responden diberikan pre tes tentang pengetahuan, sikap, dan perilaku pencegahan TB paru kemudian diberikan materi tentang TB paru dan pencegahannya, dilanjutkan diskusi permasalahan dan cara pencegahan TB paru dari masing-masing responden. Untuk menilai perilaku setelah peer education, responden diberi ceklist perilaku pencegahan TB paru dan dinilai sendiri selama tiga minggu,hasilnya akan diambil oleh peneliti. Kuesioner pengetahuan dan sikap setelah peer education diisi oleh responden pada saat bersamaan pengambilan ceklist.

Hasil penelitian dianalisis dengan menggunakan uji t-dependen untuk mengetahui pengaruh peer education terhadap perubahan perilaku pencegahan penularan $\mathrm{TB}$ paru. Uji t-independen untuk mengetahui perbedaan rata-rata perilaku pencegahan penularan TB paru pada kedua kelompok responden (Sastroasmoro, S dan Ismael, S, 2010).

\section{HASIL PENELITIAN}

Hasil penelitian dengan uji $t$ dependen dapat dilihat pada tabel 1.

Tabel 1. Pengaruh Peer Education terhadap Pencegahan Penularan TB Paru

\begin{tabular}{|c|c|c|c|c|c|c|}
\hline Kelompok & & & Mean & SD & SE & $p$-value \\
\hline \multirow{6}{*}{ Intervensi } & \multirow{2}{*}{$\mathrm{K}$} & Pre & 12.83 & 2.291 & 0.418 & \multirow{2}{*}{0.000} \\
\hline & & Post & 14.40 & 1.424 & 0.240 & \\
\hline & \multirow{2}{*}{ A } & Pre & 17.20 & 2.618 & 0.478 & \multirow{2}{*}{0.000} \\
\hline & & Post & 20.23 & 2.596 & 0.474 & \\
\hline & \multirow{2}{*}{ B } & Pre & 7.90 & 3.089 & 0.564 & \multirow{2}{*}{0.000} \\
\hline & & Post & 10.37 & 1.542 & 0.282 & \\
\hline \multirow{6}{*}{ Kontrol } & \multirow{2}{*}{ K } & Pre & 12.93 & 1.701 & 0.310 & \multirow{2}{*}{0.003} \\
\hline & & Post & 13.43 & 1.382 & 0.252 & \\
\hline & \multirow{2}{*}{ A } & Pre & 16.07 & 1.780 & 0.320 & \multirow{2}{*}{0.057} \\
\hline & & Post & 17.37 & 4.098 & 0.748 & \\
\hline & \multirow{2}{*}{ B } & Pre & 9.80 & 1.064 & 0.194 & \multirow{2}{*}{0.004} \\
\hline & & Post & 10.27 & 1.172 & 0.214 & \\
\hline
\end{tabular}

Keterangan :

$\mathrm{K}$ : Knowledge (Pengetahuan)

A : Atittude (Sikap)

B :Behavior (Perilaku) 
Tabel 1 menunjukkan bahwa pada kelompok intervensi, pengetahuan, sikap, dan perilaku didapatkan hasil $\mathrm{p}=0.000$, maka disimpulkan bahwa peer education dapat meningkatkan perilaku terhadap pencegahan penularan TB paru. Pada kelompok kontrol, menunjukkan hasil nilai $\mathrm{p}=0.003$ pada pengetahuan, $\mathrm{p}=0.057$ pada sikap, dan nilai $\mathrm{p}=0.004$ pada perilaku, maka dapat disimpulkan bahwa tanpa diberikan peer education pengetahuan dan perilaku terhadap pencegahan penularan TB paru meningkat. Hasil penelitian dengan uji $t$ independen dapat dilihat pada tabel distribusi rata-rata pengetahuan, sikap, dan perilaku responden terhadap penceghan penularan TB paru.

Tabel 2. Distribusi Rata-Rata Pengetahuan, Sikap, dan Perilaku terhadap Pencegahan Penularan TB Paru Sebelum Peer Education

\begin{tabular}{ccccccc}
\hline Var & Peer Education & Mean & SD & SE & $\boldsymbol{p}$-value & N \\
\hline \multirow{2}{*}{ K } & Ya & 12.83 & 2.291 & 0.418 & \multirow{2}{*}{0.848} & 30 \\
& Tidak & 12.93 & 1.701 & 0.310 & & 30 \\
A & Ya & 17.20 & 2.618 & 0.478 & \multirow{2}{*}{0.055} & 30 \\
& Tidak & 16.07 & 1.780 & 0.325 & & 30 \\
\multirow{2}{*}{ B } & Ya & 7.90 & 3.089 & 0.564 & \multirow{2}{*}{0.003} & 30 \\
& Tidak & 9.80 & 1.064 & 0.194 & & 30 \\
\hline
\end{tabular}

Keterangan :

$\mathrm{K}$ : Knowledge (Pengetahuan)

A : Atittude (Sikap)

B :Behavior (Perilaku)

Tabel 2 menunjukkan bahwa hasil $\mathrm{p}=0.848$ pada pengetahuan, $\mathrm{p}=0.055$ pada sikap, dan $\mathrm{p}=0.003$ pada perilaku, yang berarti bahwa tidak ada perbedaan pada pengetahuan dan sikap terhadap penularan TB paru antara responden yang diberi peer education dengan responden tanpa peer education sebelum diberikan peer education. Ada perbedaan perilaku terhadap pencegahan penularan TB paru antara responden yang diberi peer education dengan responden tanpa peer education sebelum diberikan peer education.

Tabel 3. Distribusi Rata-Rata Pengetahuan, Sikap, dan Perilaku terhadap Pencegahan Penularan TB Paru Setelah Peer Education

\begin{tabular}{ccccccc}
\hline Var & Peer Education & Mean & SD & SE & p-value & N \\
\hline \multirow{2}{*}{ K } & Ya & 14.80 & 1.424 & 0.260 & \multirow{2}{*}{0.000} & 30 \\
& Tidak & 13.43 & 1.382 & 0.252 & & 30 \\
A & Ya & 20.23 & 2.596 & 0.474 & 0.002 & 30 \\
& Tidak & 17.37 & 4.098 & 0.748 & & 30 \\
B & Ya & 10.37 & 1.542 & 0.282 & 0.778 & 30 \\
& Tidak & 10.27 & 1.172 & 0.214 & & 30 \\
\hline
\end{tabular}

Keterangan :

$\mathrm{K}$ : Knowledge (Pengetahuan)

A : Atittude (Sikap)

B : Behavior (Perilaku) 
Tabel 3 didapatkan hasil $\mathrm{p}=0.000$ pada pengetahuan, $\mathrm{p}=0.002$ pada sikap, dan $\mathrm{p}=0.778$ pada perilaku, yang berarti bahwa ada perbedaan pengetahuan dan sikap terhadap pencegahan penularan $\mathrm{TB}$ paru antara responden yang diberi peer education dengan responden tanpa peer education setelah diberikan peer education. Tidak ada perbedaan perilaku terhadap pencegahan penularan TB paru antara responden yang diberi peer education dengan responden tanpa peer education setelah diberikan peer education.

\section{PEMBAHASAN}

Hasil penelitian dengan uji tindependen menunjukkan bahwa peer education dapat meningkatkan perilaku terhadap pencegahan penularan TB paru pada kelompok intervensi, sedangkan pada kelompok kontrol tanpa diberikan peer education pengetahuan dan perilaku terhadap pencegahan penularan TB paru meningkat. Peer education dapat merubah atau meningkatkan perilaku pasien TB paru terhadap pencegahan penularan TB paru. Respon perilaku ini berbeda-beda antara pasien satu dengan pasien lainnya. Di sisi lain, pasien yang tidak mengikuti peer education kemungkinan juga akan berubah perilakunya dalam pencegahan penularan TB paru.

Pada kelompok kontrol, meskipun tidak diberikan peer education, secara tidak langsung responden sudah tersosialisasi oleh kuesioner yang berisi tentang penyakit TB paru dan pencegahan penularannya pada pengukuran pertama, sehingga saat pengukuran kedua responden mengingat kembali kuesioner yang pernah diberikan. Selain itu responden menganggap bahwa isi kuesioner yang pernah diberikan, sebagai ilmu dan pengalaman baru yang ada kaitannya dengan penyakitnya, maka responden berusaha merubah perilaku yang berkaitan dengan pencegahan TB paru.

Hasil penelitian dengan uji tindependen menunjukkan bahwa tidak ada perbedaan pengetahuan dan sikap terhadap penularan TB paru, namun ada perbedaan perilaku terhadap pencegahan penularan TB paru antara responden yang diberi peer education dengan responden tanpa peer education sebelum diberikan peer education. Setelah diberikan peer education, ada perbedaan pengetahuan dan sikap terhadap pencegahan penularan TB paru, namun tidak ada perbedaan perilaku terhadap pencegahan penularan TB paru antara responden yang diberi peer education dengan responden tanpa peer education.

Responden kelompok intervensi maupun kelompok kontrol sama-sama belum mendapatkan informasi tentang pencegahan penularan TB paru, sehingga pengetahuan dan sikap mereka tidak jauh berbeda, oleh karena itu peer education sangat diperlukan dalam memberikan informasi dan pemahaman kepada mereka. Responden yang diberi peer education mendapatkan pengalaman belajar lebih intensif dengan cara transfer informasi dan diskusi tentang TB paru dan pencegahannya bersama dengan peneliti dan peer group.

Responden tanpa peer education hanya membaca atau mendapatkan informasi sesaat pada waktu diberikan kuesioner pengetahuan dan sikap saat pengukuran pertama, sehingga pemahamannya kurang. Pengalaman belajar yang berbeda akan berpengaruh terhadap hasil belajar. Dua kelompok responden penelitian ini juga 
mendapatkan perlakuan yang berbeda, sehingga hasil penelitian juga menunjukkan ada perbedaan pada pengetahuan dan sikap, meskipun tidak ada perbedaan pada perilaku.

Tujuan akhir penanganan TB paru adalah mengurangi insiden dan menyembuhkan penderita TB paru sampai tuntas, agar Indonesia dapat terbebas dari TB paru di tahun 2030. Tindakan ini memerlukan dukungan multi sektor untuk upaya pencegahan dan pengendalian faktor risiko TB paru. Peran multi sektor sangat penting bagi keberhasilan pencapaian derajad kesehatan di masyarakat. Salah satu solusi yang dilakukan adalah mempetkuat pendampingan teman sebaya (Riono $\mathrm{P}$, 2018). Hal ini bisa dilakukan dengan peer education yang bertujuan untuk merubah perilaku pasien dalam pencegahan penularan TB paru terhadap keluarga maupun orang lain, sehingga akan menurunkan morbiditas dan mortalitas pasien TB paru.

Putra SD (2018), menyimpulkan bahwa sebuah media pembelajaran yang beragam dan menarik dapat memudahkan, disukai, dan bermanfaat bagi banyak orang, sehingga seseorang akan lebih mudah untuk mempelajari dan memahaminya. Dwi W (2016), dalam penelitiannya mengatakan bahwa peer group education berpengaruh terhadap pengetahuan tentang sadari pada remaja putri. Penelitian lain yang dilakukan oleh Rofi'ah S, Widatiningsih S, Vitaningrum D (2017), melaporkan bahwa pendidikan kesehatan dengan metode peer group efektif terhadap pengetahuan dan sikap tentang personal hygiene saat menstruasi.

Majara DM, Prastiwi S, Andinawati M (2018), dalam penelitiannya menunjukkan bahwa konseling personal dapat meningkatkan kesadaran dalam pencegahan penularan TB Paru di Wilayah Puskesmas Janti Kota Malang dengan $p$ value 0.000 . Pemberian konseling personal pada pasien TB paru, kesadaran dan kemauan pasien dalam pencegahan penularan TB paru akan meningkatkan pencegahan TB paru.

Faktor internal dan eksternal akan berpengaruh terhadap berlangsungnya dan berubahnya perilaku individu, kelompok, atau masyarakat (Mubarak dan Chayatin, 2009). Perilaku individu yang berhubungan dengan kesehatan yang bersifat posistif adalah perilaku hidup bersih sehat yaitu perilaku yang dilakukan dengan sadar dalam rangka menolong dirinya sendiri dan orang lain dalam bidang kesehatan. Gerakan masyarakat hidup sehat perlu dilakukan agar masyarakat mempunyai perilaku hidup bersih sehat dalam rangka memutus mata rantai penularan TB paru, khususnya pada pasien TB paru. Peer education menjadi media dan metode yang tepat untuk memberikan penyuluhan tentang cara memutus mata rantai penularan TB paru.

Peer education merupakan pendekatan dalam promosi kesehatan. Peer Education merupakan metode belajar dan sharing mengenai informasi kesehatan, nilai dan perilaku, saling mendidik diantaranya dengan kondisi dan permasalahan kesehatannya yang tidak jauh berbeda. Prinsip Peer education adalah bekerja menurut dasar dari, untuk, dan oleh kelompoknya, sehingga ilmu yang didapat akan membuat mereka sadar dan mau untuk merubah perilakunya. Peer education merupakan metode yang menggunakan teman sebaya atau sekelompok untuk saling mengajar dan sharing diantaranya untuk membantu anggota kelompoknya agar saling 
mendukung dalam mengatasi permasalahan yang sedang dihadapinya. Metode ini sangat sederhana, lebih efektif, komunikasi lebih terbuka, dan mereka bebas berbicara mengenai masalahannya dengan teman sekelompoknya.

Tujuan dan manfaat peer education adalah sebagai sarana dalam menyebarkan informasi tentang kesehatan khususnya tentang TB paru dan cara pencegahan penularannya, sehingga pengetahuan pasien akan bertambah. Pengetahuan yang telah didapat bisa digunakan untuk menentukan sikap dan meningkatkan perilaku pasien ke arah yang lebih baik. Pada penerapan peer education, pasien mempunyai organisasi sosial tersendiri, yang akan memberikan kesempatan kepada individu untuk melakukan perubahan dan mengembangkan sikap dan perilakunya (Simanjuntak W.R, 2014). Pemberian edukasi melalui peer education dapat digunakan untuk menjawab solusi permasalahan kelompok itu sendiri. Peer education sebagai proses awal untuk transfer informasi agar pasien dapat memahami dan menjelaskan masalah yang sedang dihadapinya melalui pemecahan masalah, dan dapat menimbulkan kesadaran berperilaku dalam pencegahan penularan TB.

\section{KESIMPULAN DAN SARAN}

Ada perbedaan yang signifikan pada pengetahuan dan sikap, tetapi tidak ada perbedaan yang signifikan pada perilaku terhadap pencegahan penularan TB paru antara responden yang diberi peer education dengan responden tanpa peer education. Di sisi lain, peer education efektif dilakukan pada pasien TB paru, karena secara signifikan dapat meningkatkan pengetahuan, sikap, dan perilaku pencegahan penularan TB paru, meskipun responden tanpa peer education, pengetahuan dan perilaku pencegahan penularan TB paru juga meningkat. Peer education dapat dijadikan program pencegahan TB paru.

\section{DAFTAR RUJUKAN}

Dwi, B.W. (2016). Pengaruh Peer Group Education tentang Sadari terhadap Tingkat Pengetahuan Remaja Putri Mengenai Sadari (Pemeriksaan Payudara Sendiri) Di SMAN 1 Gondang Kabupaten Mojokerto, 3(2), pp 6-13. Hesti Wira Sakti.

Indonesia, P.D.P. (2006). Tuberkulosis: Pedoman Diagnosis \& Penatalaksanaan di Indonesia.

Kementerian Kesehatan RI. (2018). Info datin Pusat Data dan Informasi Kementerian Kesehatan RI. Jakarta Selatan. diakses dari https://pusdatin.kemkes.go.id/resour ces/download/pusdatin/infodatin/inf odatin-tuberkulosis-2018.pdf.

Majara, D.M., Prastiwi, S., Andinawati, M. (2018). Pengaruh Konseling Personal terhadap Kesadaran Pencegahan Penularan TB Paru Di Wilayah Puskesmas Janti Kota Malang, 3(1), pp 120-132.

Mubarak dan Chayatin. (2009). Ilmu Kesehatan Masyarakat: Teori dan Aplikasi. Jakarta: Salemba Medika.

Putra, S.D. (2018). Media Pembelajaran dan Sosialisasi Penyakit TBC, 2(2), pp 76-83.

Riono, P. (2018). Eliminasi Tuberkulosis di Indonesia: Tantangan \& Peluang. 
Rofi'ah, S., Widatiningsih, S. dan Vitaningrum, D. (2017). Efektifitas Pendidikan Kesehatan Metode Peer Group terhadap Tingkat Pengetahuan dan Sikap Personal Hygiene saat Menstruasi, II(2), pp 31-36. diakses dari https://media.neliti.com/media/publi cations/227226-

efektivitaspendidikan-kesehatanmetode-1c5102d8.pdf.

Sastroasmoro, S dan Ismael, S. (2010). Dasar-Dasar Metodologi Penelitian Klinis, Edisi Ketiga. Jakarta: CV. Sagung Seto.

Simanjuntak, W.R. (2014). Peer Counseling. 